\title{
A Statistical Study on Metastable Pitting of 304 Stainless Steel in Chloride Contaminated Carbonated Concrete Pore Solution
}

\author{
Xingguo Feng ${ }^{1,2,3}$, Yiwen $\mathrm{Xu}^{1}$, Xiangying Zhang ${ }^{1}$, Xiangyu $\mathrm{Lu}^{1 *}{ }^{*}$, Leyuan Zhang ${ }^{1}$, Ruilong Shi ${ }^{1}$, \\ Jing Zhang ${ }^{1}$, Da Chen ${ }^{1}$, Xibing Zhang ${ }^{4}$ \\ ${ }^{1}$ Jiangsu Key Laboratory of Coast Ocean Resources Development and Environment Security, Hohai \\ University, Nanjing 210098, Jiangsu, China \\ ${ }^{2}$ State Key Lab of Subtropical Building Science, South China University of Technology, Guangzhou \\ 510006, China \\ ${ }^{3}$ Shangdong Provincial Key Lab of Ocean Engineering, Ocean University of China, Qingdao 266100, \\ China. \\ ${ }^{4}$ Changjiang River Scientific Research Institute, Wuhan 400010, Hubei, China \\ *E-mail: luxiangyu2013@163.com
}

doi: $10.20964 / 2018.11 .13$

Received: 14 June 2018 / Accepted: 12 Septemer 2018 / Published: 1 October 2018

\begin{abstract}
Statistical characteristics of metastable pits on 304 stainless steel in chloride contaminated carbonated pore solution was investigated via potentiodynamic and potentiostatic polarization. The peak current, pit radius and stability product of metastable pits increased; the growth rate and repassivation rate were enhanced; and the metastable pits were easier to transform to stable pits when the concentration of chloride increased in the pore solution. Additionally, extreme value statistics and cumulative probability distribution on the parameters of metastable pits follow a semi-logarithmic linear distribution, and the former present a better fitting result.
\end{abstract}

Keywords: Statistical study; pitting corrosion; stainless steel; concrete; potentiostatic polarization.

\section{FULL TEXT}

(C) 2018 The Authors. Published by ESG (www.electrochemsci.org). This article is an open access article distributed under the terms and conditions of the Creative Commons Attribution license (http://creativecommons.org/licenses/by/4.0/). 